\title{
Assessment of Payment for Ecosystem Services in Zomba Mountain Forest Catchment Area, Malawi
}

\author{
Willie Sagona ${ }^{1}$, Paxie Chirwa ${ }^{2}$, Thokozani Kanyerere ${ }^{3}$ and Herbert Jenya ${ }^{1}$ \\ 1. Forestry Research Institute of Malawi, Kufa Road, Zomba 270, Malawi \\ 2. Department of Plant Sciences, University of Pretoria, Pretoria, Hartfield 0028, South Africa \\ 3.Department of Earth Science, University of Western Cape, Robert Sobukwe Road, Bellville 7535, Republic of South Africa
}

\begin{abstract}
The emergence of Payment for Ecosystem Services (PES) concept has raised expectations that ecosystem conservation can be achieved through popular payments rather than through unpopular measures of command and control. A study on PES was conducted in Zomba Mountain Forest (ZMF) catchment area in southern Malawi between August and December 2009. The aim was to assess stakeholders' role that would promote payment for ecosystem services as a management tool. A purposive sampling was used to identify the respondents who were randomly sampled for interviews. The findings show that PES can be used as a management tool in ZMF as there are key stakeholders who benefit from the catchment area in terms of services. While there is moderate level of PES awareness among the community and other stakeholders, the current forest policy does not address PES which may derail implementation of a fully fledged PES arrangement. The study revealed that existing management challenges originate from inadequate funding that ZMF Reserve gets from government. However, this challenge offers opportunities to stakeholders through PES to contribute and participate in conserving ZMF for sustained flow of benefits.
\end{abstract}

Key words: Conservation, forest catchment, management, Payment for Ecosystem Services, stakeholders' role.

\section{Introduction}

Worldwide, valuable ecosystem services provided by forests include watershed protection, biodiversity conservation and carbon storage [1]. Dangers and costs of allowing forest services to be degraded can have local impacts, such as floods and landslides, or broader impacts, like global climate change, loss of ecosystem resilience, scenic beauty, and sources of sustainable timber and non-timber forest products. Other problems include environmental and water resource degradation resulting from physical infrastructure and landscape damage or vegetation cover deficiencies in forest catchment areas [2]. The PES has raised expectations among natural resource managers, local and national authorities, public utilities and donor organizations alike, that ecosystem conservation can be achieved through popular

Corresponding author: Willie Sagona, master, research field: forest ecosystems. payments rather than through unpopular measures of command and control [3].

Economists have argued that the conservation of tropical forests will be difficult unless custodians of these forests are compensated for the environmental services their forests provide to the wider community [4]. Efforts by upstream communities in ecosystem management need to be acknowledged by beneficiaries that make use of local ecosystems. It was earlier argued that such compensation could soon become a reality with agreement being reached under Kyoto Protocol [5].

Munk, H., et al. [1] observed in a pro-poor study that environmental conservation efforts have been evolving in recent years towards a new 'ecosystem approach' through which ecosystems are managed as a whole, with protected areas situated within a matrix of complementary land uses. This approach emphasizes the supplementary and buffering roles of forests within multiple-use landscapes [6], argued that, 
through ecosystem approach, forests and other land uses can be managed for the full range of products and services with the balance among them being determined through negotiated statements among stakeholders. The approach recognizes that local communities are an integral part of forest ecosystems and that their rights and interests should be respected. According to Scherr, S., et al. [7], the approach enables local people to take advantage of new forest market opportunities arising from PES.

Most countries in Africa lack the requisite knowledge to organize, design and implement PES effectively. It has been argued that even where sellers and buyers may be aware of the ecosystem services, the technical skills needed for PES are seldom readily available [1]. Ajayi, O. [8] observed lack of synergy among stakeholders when supporting action plans and policies for promoting environmental services such as climate change agenda. It is argued further that there is a shortage of service providers and project developers to assist with nascent PES.

Ngongondo, C. S. [9] reported that of the 450 hectares of the ZMF harvested annually, only 150 hectares are replanted. It has been reported that inadequate funding is one major problem affecting management of the forest.

The main objective of this study was to assess stakeholders' role that would promote PES as a management tool in Zomba Mountain Forest catchment area in southern Malawi. Specifically, the study i) examined stakeholder's benefits from ZMF; ii) analyzed stakeholders' contribution towards ZMF catchment area management; and iii) investigated awareness levels among stakeholders in regard to PES.

\section{Study Area}

Areas of unique scientific and geographical significance on the Zomba Mountain (Fig. 1), which lies within $15^{\circ} 19^{\prime} 0^{\prime \prime} \mathrm{S}$ and $35^{\circ} 18^{\prime} 55^{\prime \prime} \mathrm{E}$, include the
Zomba Mountain Forest (ZMF) reserve which is a protected area and Mulunguzi River and marshes that constitute the wetlands on the plateau [9]. The ZMF catchment area occupies an area of approximately $18.2 \mathrm{~km}^{2}$ and is mostly covered with a pine plantation. Other major land uses on the ZMF over the years include silvopastoral and eco-tourism [9].

\section{Methodology and Data}

Descriptive research design was used in this study in order to generate a hypothesis on the effectiveness of using PES as a management tool. Such a designis valuable in social research where a researcher's goals focuses on exploring associations between attitudes, behaviors and experiences of people; developing explanations about the studied concepts (PES) and then generate new ideas and theories in addition to attempting to discover general information about PES [10]. Six villages were purposively sampled due to their proximity to ZMF as they shared boundaries with ZMF. The sample size was composed of 60 randomly selected respondents with household as a unit of analysis. In addition, three focus group discussions with the members of Village Development Committees (VDC) were done, one in TA Malemia area and two in TA Mlumbe. Key informants from different institutions that have a stake in the ZMF were also interviewed.

Asemi-structured questionnaire was administered to the Forestry Department which represented the government in order to identify other stakeholders and the existing catchment management arrangements that seeks to regulate flow of ecosystem services. The interview guide was used to collect data from members of the surrounding community to identify major beneficiaries from Zomba Mountain Forest ecosystem; contributions towards ZMF catchment area management; and awareness levels among stakeholders of PES. Focus group discussions were conducted to collect data on the perception of members of VDC on PES. 


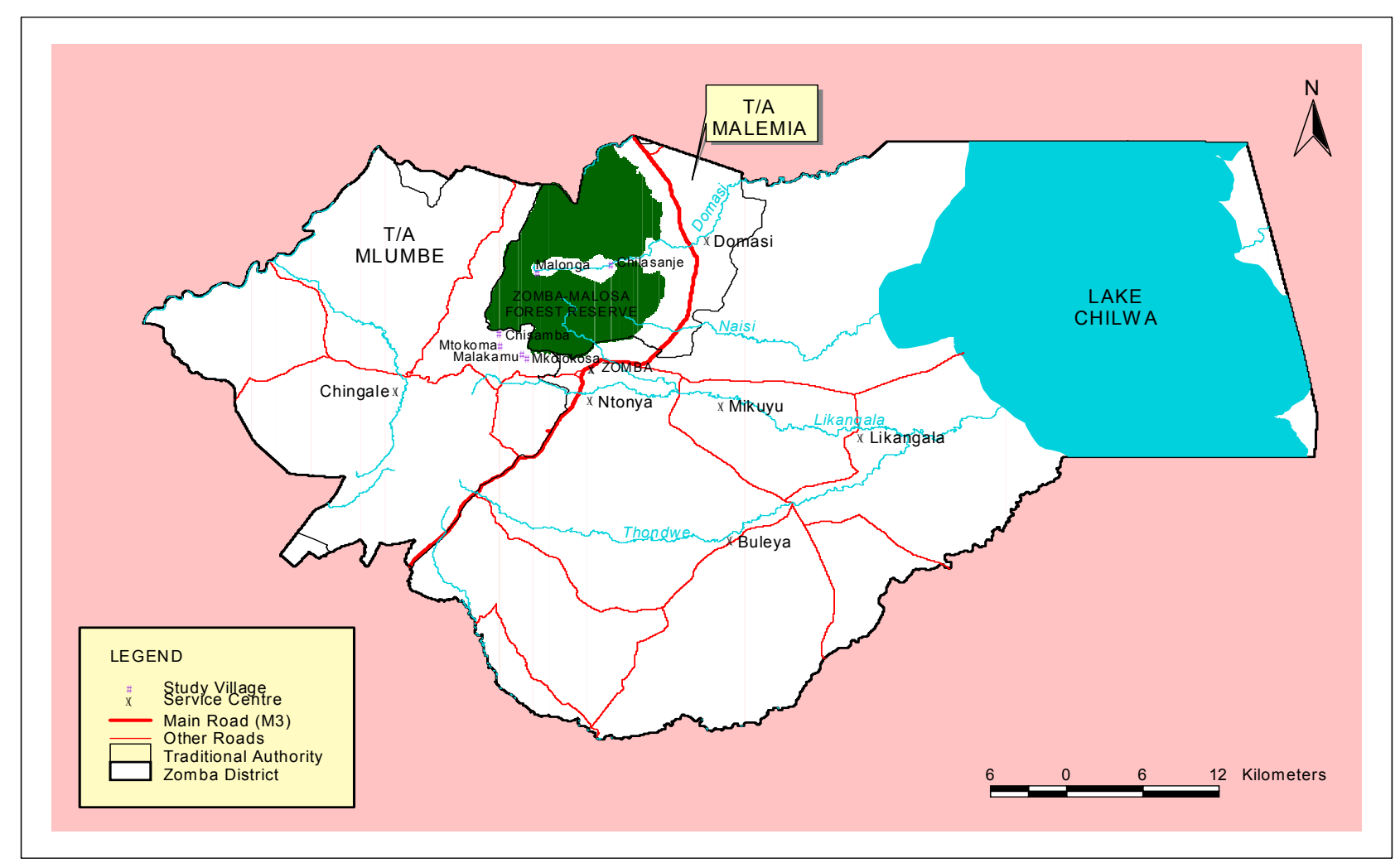

Fig. 1 Zomba district showing Zomba Mountain Forest and villages under study.

\section{Data Analysis}

Data was analyzed using Statistical Package for Social Scientists (SPSS 11.5 version) [11]. Quantitative data was analyzed using descriptive statistics where frequencies, skewness and kurtosis were used to determine the distribution of responses. Cross tabulation was used to determine levels of significance using Chi-Square Tests [12]. Qualitative data, collected through observation techniques and focus group discussion, was analyzed using thematic andcontent analyses. The interpretation complemented the quantitative analysis that gave a credible meaning.

\section{Results}

\subsection{Stakeholders Benefits from ZMF}

The results (Table 1) signify the importance of ZMF catchment area to the surrounding community's livelihoods. All community members (100\%) indicated that they get benefits from the ZMF catchment area. The main benefits include water supply (88\%), wood supply (85\%) and medicinal plants $(80 \%)$. There was a significant $(\mathrm{p} \leq 0.05)$ difference between sexes on the aesthetic value of the catchment areas. There were also significant differences $(p \leq 0.05)$ between traditional authorities on the value of the catchment for products such as poles, wild fruits and medicinal plants.

\subsection{Stakeholders' Contribution to Forest Catchment Management}

Any individual, group or business either from within or outside with a vested interest in the ZMF is considered to be a stakeholder. A majority of community respondents $(88 \%)$ indicated that they have contributed towards ZMF catchment management. Among the contributions (Table 2) are license and fees $(80 \%)$, voluntary forest protection $(42 \%)$ and tourism promotion $(40 \%)$. There were significant differences $(p \leq 0.05)$ in contributions to tourism promotion between men and women. There were also significant differences $(p \leq 0.05)$ in contributions 
Table 1 Major benefits to communities from ZMF.

\begin{tabular}{lllllll}
\hline & Water supply & Wood supply & Aesthetic value & Poles & Wild fruits & Medicinal plants \\
\hline N value & 60 & 60 & 60 & 60 & 60 & 60 \\
Respondents (\%) & 88 & 85 & 5 & 30 & 25 & 80 \\
Skewness & 2.45 & 2.01 & -4.24 & 0.895 & 1.19 & 1.54 \\
Kurtosis & 4.14 & 2.11 & 16.49 & -1.24 & -0.62 & 0.38 \\
\hline
\end{tabular}

Table 2 Community contributions towards catchment management.

\begin{tabular}{llll}
\hline Statistics & License and fees & Voluntary forest protection & Tourism promotion \\
\hline $\mathrm{N}$ & 60 & 60 & 60 \\
Respondents (\%) & 80 & 42 & 40 \\
Skewness & 1.54 & -0.35 & -0.42 \\
Kurtois & 0.38 & -1.95 & -1.89 \\
\hline
\end{tabular}

tolicense and fees and voluntary forest protection betweentraditional authorities Malemia and Mlumbe. Although the community's contribution towards management seems to be inadequate, all respondents $(100 \%)$ indicated that any further catchment degradation would seriously affect their livelihood. They associated further degradation with decline of water supply (53\%), fuel wood scarcity (90\%) and loss of source of income $(85 \%)$. In order to reverse catchment degradation, $57 \%$ of the communities suggested that some management tools in the form of PES should be used in ZMF. There were, however, significant differences $(p \leq 0.05)$ between two Traditional Authorities of Mlumbe and Malemia. Majority $(100 \%)$ of respondents were not in favor of privatization of $\mathrm{ZMF}$.

\subsection{Awareness Levels among Stakeholders in Regard to $P E S$}

Some community respondents $(47 \%)$ indicated that they are aware of PES concept. More than $90 \%$ of the respondents felt that institutions deriving income from the ZMF such as the water board saw millers and tourism sector should be paying for the ecosystem services. In addition, $97 \%$ of the respondents wanted these institutions to fulfill certain social responsibilities such as building rural clinics $(85 \%)$, portable water supply (55\%) and employment creation $(83 \%)$.
While all respondents $(100 \%)$ indicated that management challenges exist in $\mathrm{ZMF}, 82 \%$ of them felt that stakeholders in ZMF have not helped to sustainably manage the resources. The major ZMF management challenges included illegal logging $(85 \%)$, forest fires $(100 \%)$, over cutting $(65 \%)$, little or no replanting (63\%) and reduced laborinput (93\%). These challenges in turn affected the community through forest resource depletion (87\%), water quantity and quality reduction (67\%) and local climate variability (57\%). Nearly half of the respondents felt that PES approach can help improve ZMF catchment management. The perception on the use of PES as a management tool for ZMF catchment area had a significant difference $(\mathrm{p} \leq 0.05)$ between Traditional Authorities Malemia and Mlumbe. This could be attributed to varying levels of awareness of PES between Traditional Authorities. However, reasons cited for improved management due to PES include multi-sectoral responsibility (47\%) and improved ecosystem conservation (43\%).

\section{Discussion}

The main contribution of forest resources to rural livelihoods is through providing subsistence products and services, and a de facto "safety net." Hussein, K., et al. [13, 14] observed that the majority of rural population in developing countries have survived and reproduced by growing a mix of staple and cash crops, 
irrigation farming, fishing and gathering forest products. Similar findings on the benefits of forest ecosystems to the rural people living in the forest margins have been reported by several scholars [15-17].

The significant contribution to the catchment management through license and fees could be due to the strict enforcement of the forestry patrol personnel on all individuals collecting forest products such as firewood or logging for timber. However, non timber forest products such as water, medicinal plants, mushroom and fruits are collected for free by the community. Voluntary forest protection is mainly done during fire season when there is an occurrence of fire in ZMF. The surrounding communities take part in the promotion of tourism through tourist guiding and sales of different merchandise such as precious stones, curios, wild flowers and wild fruits to those visiting the plateau.

None of the respondents supported privatization of ZMF. This could be due to fear of community exclusion as investors under privatization usually try to maximize profits through exclusion. Previous attempts at privatization of ZMF coordinated by Forest Plantation Initiative Malawi (FPIM) failed to materialize as it was not approved by the Malawi government [18]. For the majority of ecosystem services that are "public goods" the creation of PES requires proactive efforts on the part of governments and non-government actors. At its 2003 meeting in Locarno, Switzerland, The Katoomba Group concluded that lack of policy frameworks was one of the most critical overall barriers to the expansion of PES into other regions [3]. The results indicate that PES, in the face of competing land uses, will require that local people should continue to obtain some direct or indirect ecosystem benefits while taking part in its conservation efforts [19].

The study has shown that the private sector represent a critical opportunity for catchment conservation through PES. This is because the combined potential scale of private sector payments may exceed current and potential investments by Forestry Department. For example, a number of investors in ZMF such as Sothern Region Water Board (SRWB), Sunbird Kuchawe Hotel, Cottages and the Trout fish farm thrive on ZMF catchment area. Lessons can be drawn from Tanzania Electricity Supply Company (TANESCO) where user fee is paid towards basin management [20]. However, in Malawi, a meaningful level of private sector involvement may not materialize until proper policies and institutional arrangements to regulate PES are put in place. The Malawi forestry policy of 1996 is silent on PES thus making it optional or voluntary for different stakeholders to contribute towards catchment management. A review of PES in developing countries [3] concluded that there is a need for much more strategic consideration to implement PES, so that it complements other policy instruments. It requires a strategic assessment of PES based on input from stakeholders of existing incentives, financial resources and regulatory capacity to guide the PES process and even highlight those areas where PES could be especially promising.

The study findings agree with Molnar, A., et al. [21] argument that simple contracts offering social services rather than payments can by themselves be more effective in securing ecosystem services flow from land and resource stewards. The findings reinforce the views of Scherr, S., et al. [15] that PES mechanisms can be used to give rural communities a new social role as ecosystem service managers for ecosystems under stress. The results show that PES schemes fit within the larger picture of rural development which will also help policymakers to better prioritize and understand the relationships between ecosystem services/degradation and rural development within ZMF. Scherr, S., et al. [19] observed that PES will be politically acceptable only where all the parties agree, or at least accept and are willing to sustain flow of ecosystem services and have confidence in the 
long-term security of the PES arrangements. For example, SRWB who believe they have the right to high quality water may be unwilling to pay FD for improving degraded catchment area. Alternatively, if ZMF is acknowledged to have degraded the catchment area for the sake of generating government revenue, changing their routine logging operations may require cash or kind contributions from all other beneficiaries through PES.

\section{Conclusion}

The findings from the study have shown that PES arrangement can work as a management tool for ZMF catchment area because at least stakeholders accept and are willing to protect their catchment area. Overall the study illustrates the importance of implementing PES as a management tool in the study catchment area. The communities acknowledged that the catchment area provides them with subsistence products and services as a source of their livelihoods and further degradation of ZMF greatly endanger their life support system. Results have shown different ways how the stakeholders have contributed towards managing the catchment area and view PES as an option for sustainable management of their forest. Although non timber products are collected for free, respondents were of the views that institutions that financially benefits from the forest products must pay for such products and services. The outcome of this study supports findings from various studies that reject privatization as a tool for managing catchment area sustainably. Findings from this study show that despite the non-existence of the policy on PES in Malawi, guidelines that can be developed from a study like this one and implement the use of PES as a management tool would be effective in sustainable management of the forest. This would be an important progression towards achieving sustained management of catchment areas that provide ecosystem services to the stakeholders who accrue direct and indirect benefits.

The study demonstrated the usefulness of implementing PES concept as a solution to the management challenges that occur due to inadequate funding from the government. Such findings provide insights on how feasible the implementation of PES would be when given opportunity to scale it up in other catchment areas in the country and beyond.

Lastly, the study has shown the necessity of involving all stakeholders in assessing the significance of the ZMF to propose solutions that would enable continuous supply of product and service benefits from the forest. Analysis of stakeholder benefits from a mountain forest provides a basis for considering valuation of forest ecosystem services so that they are incorporated into national accounts.

\section{Acknowledgements}

The authors thank United Nations Development Program-Malawi Office for funding this study through Forestry Research Institute of Malawi (FRIM) and Leadership in Environment and Development (LEAD) of Chancellor College. All participants in the study are thanked for their cooperation and support.

\section{References}

[1] Munk, H., Mette, R., Damsgaard, G., and Raben, K. 2007. Payment for Ecosystem Services: Issues and Pro-Poor Opportunities for Development Assistance. Copenhagen: Danish Institute for International Studies (DIIS) press.

[2] Waage, S. 2006. Mainstreaming Payments for Ecosystem Services in the Developing World. A Tale of Two Continents: Technical report. Ecosystem Services in Latin America and East and Southern Africa.

[3] The Katoomba Group. 2007. Current 'State of Play' of Carbon, Water and Biodiversity Markets. Forest Trends, Washington, DC, USA.

[4] Pearce, D. 1996. "Global Environmental Value and the Tropical Forests: Demonstration and Capture." In Proceedings of Forestry, Economics and the Environment, CAB International, 11-49.

[5] Smith, J., and Scherr, S. J. 2002. "Forest Carbon and Local Livelihoods: Assessment of Opportunities and Policy Recommendations." In Proceedings of CIFOR Occasional Paper, 37: 45.

[6] Wunder, S. 2005. "Payments for Environmental Services: 
Some Nuts and Bolts." In Proceedings of CIFOR Info. Brief 9.

[7] Scherr, S., White, A., and Kaimowitz, D. 2002. "Making Forest Markets Work for Low-income Producers." Forest Trends and CIFOR.

[8] Ajayi, O. 2008. "Agroforestry for Promoting Food Security and Environmental Services in Malawi." Presented at Payment for Ecosystem Workshop, Lilongwe, Malawi.

[9] Ngongondo, C. S. 2006. "An Analysis of Rainfall Trends, Variability and Groundwater Availability in Mulunguzi River Catchment Area, Zomba Mountain, Southern Malawi." Quat. Int. 148: 45-50.

[10] Kitchin, R., and Tate, N. J. 2000. Conducting Research into Human Geography: Theory, Methodology and Practice. London: Pearson Education limited.

[11] Brace, N., Kemp, R., and Snelgar, R. 2000. SPSS for Psychologists. A Guide to Data Analysis using SPSS for Windows. NewYork: Palgrave.

[12] Wonnacott, R. J., and Wonnacott, T. H. 1985. Introductory Statistics. New York: John Wiley and Sons.

[13] Hussein, K., and Nelson, J. 1999. "Sustainable Livelihoods and Diversification." IDS Working Paper, London, UK.

[14] Ellis, F. 2000. Rural Livelihoods and Diversity in Developing Countries. Oxford: University of Oxford Press.
[15] Scherr, S., White, A., and Khare, A. 2004. For Services Rendered: The Current Status and Future Potential of Markets for the Ecosystem Services Provided by Tropical Forests. International Tropical Timber Organization (ITTO).

[16] Molnar, A., and White, A. 2001. "Forestry and Land Management." In Mexico: A Comprehensive Development Agenda for the New Era, edited by Guigale, M. M., Lafourcade, O. and Nguyen, V. (Eds.). Washington, DC: The World Bank.

[17] Wunder, S. 2000. Poverty Alleviation and Tropical Forests: What Scope for Synergies? World Development report.

[18] Department for International Development (DfID). 2006. Malawi Forest Sector Support Program (MFSSP). Project Completion report, Lilongwe, Malawi.

[19] Scherr, S., White, A., and Kaimowitz, D. 2001. "Making Markets Work for Forest Communities." The International Forestry Review 5 (1): 67-73.

[20] Scurrah, C. 2006. Tanzania Inventory of Payment for Ecosystem Services. Washington, DC: Forest Trends.

[21] Molnar, A., White, A., Scherr, S., Bracer, C., Sekher, M., Owuor Ochieng B., and Sriskanthan, G. 2006. "Organization and governance for fostering pro-poor CES." In Proceedings of International Development Research Council (IDRC) 4. 